\section{RMD Open}

Rheumatic \& Musculoskeletal Diseases

\title{
Atorvastatin is unlikely to prevent rheumatoid arthritis in high risk individuals: results from the prematurely stopped STAtins to Prevent Rheumatoid Arthritis (STAPRA) trial
}

To cite: van Boheemen L, Turk S Beers-Tas M, et al. Atorvastatin is unlikely to prevent rheumatoid arthritis in high risk individuals: results from the prematurely stopped STAtins to Prevent Rheumatoid Arthritis (STAPRA) trial. RMD Open 2021;7:e001591. doi:10.1136/ rmdopen-2021-001591

- Prepublication history and additional material is published online only. To view please visit the journal online (http://dx.doi. org/10.1136/rmdopen-2021001591).

Received 19 January 2021 Revised 23 February 2021 Accepted 23 February 2021

\section{Check for updates}

C) Author(s) (or their employer(s)) 2021. Re-use permitted under CC BY-NC. No commercial re-use. See rights and permissions. Published by BMJ.

For numbered affiliations see end of article.

Correspondence to Dr Laurette van Boheemen; I.vanboheemen@ amsterdamumc.nl

\section{Laurette van Boheemen (D) , Samina Turk, ${ }^{1}$ Marian van Beers-Tas (D) , ${ }^{1}$ Wouter Bos, ${ }^{1}$ Diane Marsman (1) , ${ }^{2}$ Ed N Griep, ${ }^{3}$ Mirian Starmans-Kool, ${ }^{4}$ Calin D Popa (D) , ${ }^{5,6}$ Alper van Sijl, ${ }^{1}$ Maarten Boers (D) , ,,8 Michael T Nurmohamed (D) ,1,8 Dirkjan van Schaardenburg (i) 1,9}

\section{ABSTRACT}

Objectives Persons at high risk of rheumatoid arthritis (RA) might benefit from a low-risk pharmacological intervention aimed at primary prevention. Previous studies demonstrated disease-modifying effects of statins in patients with RA as well as an association between statin use and a decreased risk of RA development. A randomised, double-blind, placebo-controlled tria investigated whether atorvastatin could prevent arthritis development in high-risk individuals.

Methods Arthralgia patients with anticitrullinated protein antibody (ACPA) $>3$ XULN or ACPA and rheumatoid factor, without (a history of) arthritis, were randomised to receive atorvastatin $40 \mathrm{mg}$ daily or placebo for 3 years. The calculated sample size was 220 participants. The primary endpoint was clinical arthritis. Cox regression analysis was used to determine the effect of atorvastatin on arthritis development.

Results Due to a low inclusion rate, mainly because of an unwillingness to participate, the trial was prematurely stopped. Data of the 62 randomised individuals were analysed. Median follow-up was 14 (inner quartiles 6-35) months. Fifteen individuals (24\%) developed arthritis: $9 / 31$ $(29 \%)$ in the atorvastatin group; $6 / 31(19 \%)$ in the placebo group: HR $1.40,95 \% \mathrm{Cl} 0.50$ to 3.95

Conclusions In this small set of randomised high-risk individuals, we did not demonstrate a protective effect of atorvastatin on arthritis development. The main reason for the low inclusion was unwillingness to participate; this may also impede other RA prevention trials. Further research to investigate and solve barriers for prevention trial participation is needed.

\section{INTRODUCTION}

Individuals at high risk of rheumatoid arthritis (RA) might benefit from a pharmacological intervention aimed at primary prevention. The opportunity for preventive

\section{Key messages}

What is already known about this subject?

- Previous studies demonstrated disease-modifying effects of statins in rheumatoid arthritis (RA) as well as an association between statin use and a decreased risk of RA development.

What does this study add?

- The current study of atorvastatin to prevent RA was underpowered and results are inconclusive.

- Unwillingness to participate in RA prevention trials is a major problem, as is also noted in other completed and ongoing RA prevention trials.

How might this impact on clinical practice?

- To better understand the recruitment challenge and to devise strategies to overcome this problem, studies are needed to further investigate and solve barriers for RA prevention trial participation.

intervention is provided by the recognition of a preclinical or at-risk phase in RA: a period of disease development before clinical arthritis onset, where characteristic symptoms and biomarkers are often already present. ${ }^{1}$ Using such characteristics, high-risk individuals for preventive intervention trials can be identified. $^{2}$

The lower inflammatory burden in the preclinical versus the early arthritis phase of RA may allow inhibition of disease development with less potent medication. Moreover, due to the inherent risk of overtreatment in the at-risk stage, a relatively non-toxic and easy to administer drug would be preferred. Statins are safe and widely used lipid-lowering agents that also have anti-inflammatory 
properties including suppression of dendritic cell maturation, induction of suppressor regulatory $\mathrm{T}$ cells, and suppression of proinflammatory cytokine release. ${ }^{3}$ Statins were demonstrated to have disease modifying effects in RA, including decreased inflammatory parameters and improved disease activity scores. ${ }^{4}$ On the population level an association between statin use and a decreased risk of RA development has been demonstrated $^{56}$ and statins showed protective effects in murine RA models. ${ }^{78}$ Additionally, cardiovascular disease (CVD) is the most common comorbid condition in $\mathrm{RA}^{9}$ and the increased CVD risk is already present at the time of RA diagnosis, ${ }^{10-12}$ strengthening the rationale for exploring statins as a potential tool for RA prevention. Therefore, we designed a multicentre, randomised, double-blind, placebo-controlled trial to investigate whether atorvastatin $40 \mathrm{mg}$ per day for 3 years could prevent arthritis development in individuals at high risk of RA (STAtins to Prevent Rheumatoid Arthritis (STAPRA) trial: trialregister.nl, NTR5265).

\section{METHODS}

Consecutive arthralgia patients aged $\geq 18$ years old at high risk of RA, defined by anticitrullinated protein antibodies (ACPA) $>3 x$ the upper limit of normal $(\geq 21 \mathrm{kU} / \mathrm{L}$ ) or both ACPA $(\geq 7 \mathrm{kU} / \mathrm{L})$ and rheumatoid factor $(\mathrm{RF} ; \geq 5 \mathrm{kU} / \mathrm{L})$, with no history of clinically diagnosed arthritis, were recruited at five rheumatology clinics across the Netherlands between November 2015 and January 2019. The study protocol is shown in online supplemental file 1 . The sample size was set at 220, based on an expected RA risk of $55 \%$ within 3 years $^{25}$; a risk reduction of $21 \%{ }^{5}$; a two-sided $5 \%$ level of confidence $(\mathrm{p}<0.05) ; 80 \%$ power and a $10 \%$ attrition rate. The primary outcome was clinical arthritis development, defined as $\geq 1$ swollen joint (swollen joint count of 44 joints) as observed by two independent investigators. The secondary outcome was fulfilment of the 2010 ACR/EULAR classification criteria for RA. Baseline characteristics were explored with descriptive statistics. Cox regression analysis was used to determine the effect of atorvastatin on arthritis development. Primary analysis was by intention-to-treat (ITT), second, a per-protocol (PP) analysis was performed.

\section{RESULTS}

The trial suffered severe difficulties with patient inclusion, mainly due to an unwillingness to participate. The main reasons were unwillingness to use study medication and the perceived high study burden. In total, 175 eligible at-risk individuals were identified, of whom 108 declined participation (figure 1). Inclusion was stopped prematurely after 39 months due to the low inclusion rate. Four patients were ineligible at screening, and 1 withdrew participation before randomisation; 62 individuals were randomised. Baseline characteristics of the atorvastatin group $(n=31)$ and the placebo group $(n=31)$ are shown in table 1 . Study protocol adherence is shown in figure 1 . Numerically more patients dropped out in the placebo group (atorvastatin: $19 \%$, placebo: $36 \%, \mathrm{p}=0.16$ ), groups were similar regarding median follow-up (atorvastatin: 17 (IQR 6-28) months, placebo: $14(5-36)$ months, $\mathrm{p}=0.70)$ and duration of medication use (8 (5-26) months and 8 (3-17) months, respectively,

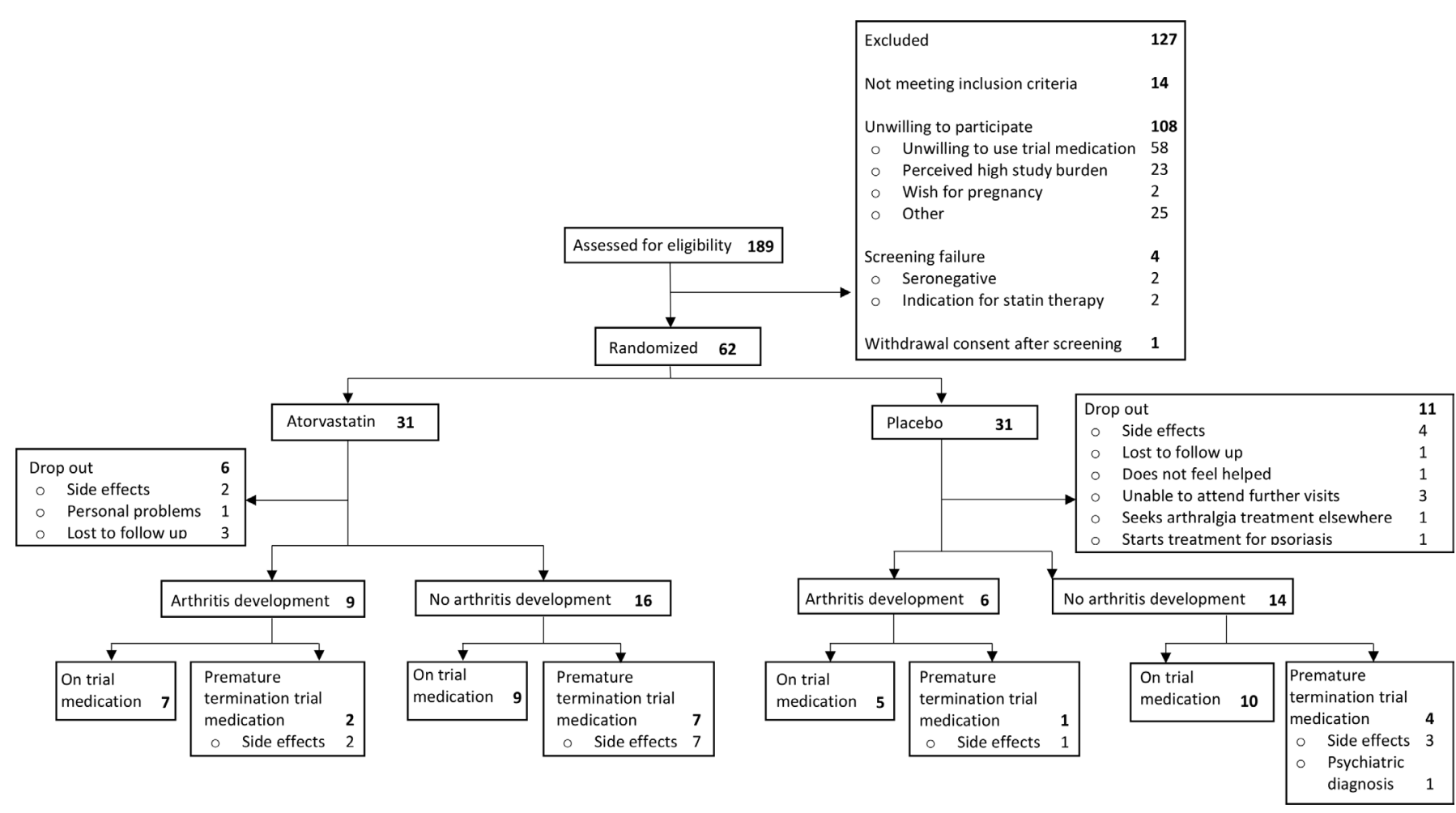

Figure 1 STAPRA study flow chart. STAPRA, STAtins to Prevent Rheumatoid Arthritis. 
Table 1 STAPRA study baseline characteristics

\begin{tabular}{lcc}
\hline & Atorvastatin $\mathbf{n = 3 1}$ & \multicolumn{1}{c}{$\begin{array}{l}\text { Placebo } \\
\mathbf{n}=\mathbf{3 1}\end{array}$} \\
\hline Age, mean (SD) & $49(8)$ & $46(11)$ \\
Female sex, $\mathrm{n}(\%)$ & $21(68)$ & $25(81)$ \\
\hline Current smoker, $\mathrm{n}(\%)$ & $11(36)$ & $13(42)$ \\
\hline Current alcohol use, $\mathrm{n}(\%)$ & $16(52)$ & $23(74)$ \\
BMI, mean (SD) & $25.9(5.2)$ & $27.0(5.7)$ \\
RF positive, n (\%) & $23(74)$ & $17(55)$ \\
RF level, median (IQR) & $19(42)$ & $10(44)$ \\
ACPA positive, n (\%) & $31(100)$ & $31(100)$ \\
ACPA level, median (IQR) & $304(551)$ & $146(304)$ \\
CRP, median (IQR) & $2(1.8)$ & $2(3.8)$ \\
ESR, median (IQR) & $10(14)$ & $7(7)$ \\
VAS global disease & $32(55)$ & $29(55)$ \\
activity, median (IQR) & & $1(2)$ \\
\hline TJC, median (IQR) & $0(2)$ & \\
\hline
\end{tabular}

ACPA, anticitrullinated protein antibody; BMI, body mass index; CRP, C reactive protein; ESR, erythrocyte sedimentation rate; RF, rheumatoid factor; STAPRA, STAtins to Prevent Rheumatoid Arthritis; TJC, tender joint count; VAS, Visual Analogue Scale.

$\mathrm{p}=0.52$ ). One participant dropped out and two participants stopped trial medication prematurely for medical reasons (diagnosed psoriasis, chronic ALT elevation and psychiatric diagnosis, respectively), all others did so on their own initiative. The main reason for drop-out and discontinuation of study medication was perceived side effects, most commonly muscle pains or cramps $(37 \%$ of all reported side effects, $\mathrm{n}=10$ in both groups). In total, there were 48 adverse events

\section{Arthritis-free survival}

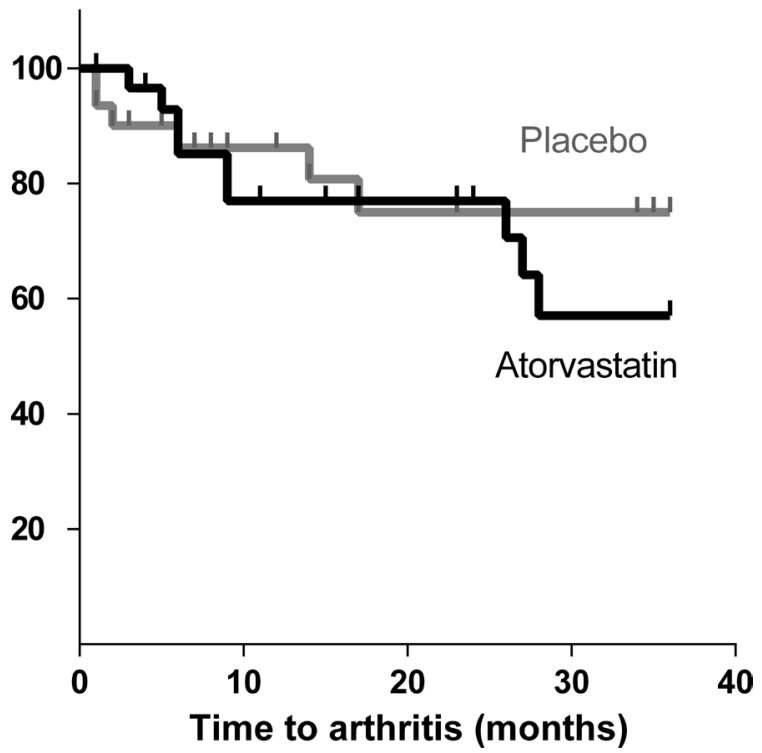

Figure 2 Kaplan-Meier arthritis-free survival curves of atorvastatin and placebo groups by intention-to-treat analysis. in the atorvastatin arm (49\%) and 49 in the placebo arm (51\%; online supplemental file 2).

Fifteen individuals (24\%) developed arthritis: 9/31 (29\%) in the atorvastatin group and 6/31 (19\%) in the placebo group, after a median period of 9 (6-27) months and 4 $(0-15)$ months, respectively. The arthritis-free survival plot is shown in figure 2. No significant difference in arthritis development or time until arthritis was observed between groups: ITT analysis: HR 1.40 (95\% CI 0.50 to 3.95); PP analysis: HR 1.19 (95\% CI 0.38 to 3.76). Fourteen individuals fulfilled the 2010 ACR/EULAR classification criteria for RA: 8 (26\%) in the atorvastatin group and 6 (19\%) in the placebo group: ITT analyses HR 1.26 (95\% CI 0.44 to 3.63 ).

\section{DISCUSSION}

In this small set of randomised patients, we failed to demonstrate a protective effect of atorvastatin on arthritis development in high-risk individuals. In fact, placebo patients were numerically better off. However, we failed to achieve the required sample size: the number of at-risk individuals willing to participate was much lower than expected. Of all eligible individuals, $62 \%$ declined participation. An unwillingness to use trial medication (58\%) or a perceived high study burden $(23 \%)$ were the most frequently mentioned reasons. In addition we experienced a high drop-out rate, mainly due to side effects, of which muscle symptoms were the most frequently mentioned. These side effects occurred equally in both groups, confirming previous research showing the nocebo effect of statins. ${ }^{13}$

The STAPRA trial design was based on large population studies showing protective effects of statin use on RA development. ${ }^{56}$ Since then, other studies on statin use and RA development produced conflicting results, ${ }^{14-17}$ partly due to selection bias and confounding. Unfortunately, our trial cannot resolve the issue.

The unwillingness to participate in the current trial is in line with the experience in other completed (testing dexamethasone; rituximab) and ongoing (testing abatacept; hydroxychloroquine) RA prevention trials, some needing up to 5 years to achieve their recruitment aims $^{18-20}$ (ClinicalTrials.gov NCT02603146). It contrasts with the relative ease with which early RA trials recruit patients. It may be that the perceived urgency and preferences of individuals regarding treatment are inadequately addressed in the prevention trials, but successful completion of such trials is crucial for progress in the field of RA prevention. Therefore, the recruitment difficulties in prevention trials need urgent attention: barriers for participation need to be explored and addressed.

\section{CONCLUSIONS}

This inconclusive trial of a low impact intervention to prevent RA highlights recruitment and retention issues. Such issues must be resolved for RA prevention to move forward. 
Author affiliations

${ }^{1}$ Rheumatology, Reade, Amsterdam Rheumatology and Immunology Center, Amsterdam, Noord-Holland, The Netherlands

${ }^{2}$ Rheumatology, Sint Maartenskliniek, Nijmegen, The Netherlands

${ }^{3}$ Rheumatology, Antonius Hospital Sneek, Sneek, The Netherlands

${ }^{4}$ Rheumatology, Zuyderland Medisch Centrum Heerlen, Heerlen, The Netherlands

${ }^{5}$ Rheumatology, Bernhoven Hospital Location Uden, Uden, The Netherlands

${ }^{6}$ Rheumatology, Radboudumc, Nijmegen, The Netherlands

${ }^{7}$ Epidemiology and Data Science, Amsterdam Public Health, Amsterdam UMC Locatie VUmc, Amsterdam, Noord-Holland, The Netherlands

${ }^{8}$ Rheumatology and immunology, AI\&l, Amsterdam UMC Locatie VUmc, Amsterdam, Noord-Holland, The Netherlands

${ }^{9}$ Rheumatology, Amsterdam UMC Locatie AMC, Amsterdam, The Netherlands

Twitter Marian van Beers-Tas @no

Contributors DvS, MTN, MvB-T, AVS and ST designed the study. LvB, ST, MB, WB, DM, ENG, MS-K and CDP contributed to data collection. LvB, MvB-T, MTN and DvS contributed to data analyses and interpretation. All authors reviewed the manuscript and approved the final version for submission. Shared last authorship MTN and DvS.

Funding This study was funded by the Dutch Arthritis Society, grant number 13-1501.

Competing interests None declared.

Patient consent for publication Not required.

Ethics approval The study was conducted in accordance with the ethical principles of the Declaration of Helsinki and Good Clinical Practice guidelines and approved by the institutional review boards of each centre involved and the ethics committee of the Slotervaart Hospital and Reade, Amsterdam, The Netherlands (NL47550.048.13).

Provenance and peer review Not commissioned; externally peer reviewed.

Data availability statement The datasets used during the current study are available from the corresponding author on reasonable request.

Open access This is an open access article distributed in accordance with the Creative Commons Attribution Non Commercial (CC BY-NC 4.0) license, which permits others to distribute, remix, adapt, build upon this work non-commercially, and license their derivative works on different terms, provided the original work is properly cited, appropriate credit is given, any changes made indicated, and the use is non-commercial. See: http://creativecommons.org/licenses/by-nc/4.0/.

ORCID iDs

Laurette van Boheemen http://orcid.org/0000-0003-3168-548X

Marian van Beers-Tas http://orcid.org/0000-0002-4200-2894

Diane Marsman http://orcid.org/0000-0002-3103-1374

Calin D Popa http://orcid.org/0000-0001-9470-9720

Maarten Boers http://orcid.org/0000-0002-6969-283X

Michael T Nurmohamed http://orcid.org/0000-0002-6274-1934

Dirkjan van Schaardenburg http://orcid.org/0000-0003-4006-3762

\section{REFERENCES}

1 Gerlag DM, Raza K, van Baarsen LGM, et al. EULAR recommendations for terminology and research in individuals at risk of rheumatoid arthritis: report from the study Group for risk factors for rheumatoid arthritis. Ann Rheum Dis 2012;71:638-41.

2 van de Stadt LA, Witte BI, Bos WH, et al. A prediction rule for the development of arthritis in seropositive arthralgia patients. Ann Rheum Dis 2013;72:1920-6.

3 Shahbaz SK, Sadeghi M, Koushki K, et al. Regulatory T cells: possible mediators for the anti-inflammatory action of statins. Pharmacol Res 2019;149:104469.

4 Li G-M, Zhao J, Li B, et al. The anti-inflammatory effects of statins on patients with rheumatoid arthritis: a systemic review and meta-analysis of 15 randomized controlled trials. Autoimmun Rev 2018;17:215-25.

5 Jick SS, Choi H, Li L, et al. Hyperlipidaemia, statin use and the risk of developing rheumatoid arthritis. Ann Rheum Dis 2009;68:546-51.

6 Chodick G, Amital H, Shalem Y, et al. Persistence with statins and onset of rheumatoid arthritis: a population-based cohort study. PLOS Med 2010;7:e1000336.

7 Palmer G, Chobaz V, Talabot-Ayer D, et al. Assessment of the efficacy of different statins in murine collagen-induced arthritis. Arthritis Rheum 2004;50:4051-9.

8 Yamagata T, Kinoshita K, Nozaki Y, et al. Effects of pravastatin in murine collagen-induced arthritis. Rheumatol Int 2007;27:631-9.

9 Nurmohamed MT, Heslinga M, Kitas GD. Cardiovascular comorbidity in rheumatic diseases. Nat Rev Rheumatol 2015;11:693-704.

10 Kerola AM, Kauppi MJ, Kerola T, et al. How early in the course of rheumatoid arthritis does the excess cardiovascular risk appear? Ann Rheum Dis 2012;71:1606-15.

11 Holmqvist M, Ljung L, Askling J. Acute coronary syndrome in newonset rheumatoid arthritis: a population-based nationwide cohort study of time trends in risks and excess risks. Ann Rheum Dis 2017:76:1642-7.

12 van Boheemen L, van Beers-Tas MH, Kroese JM, et al. Cardiovascular risk in persons at risk of developing rheumatoid arthritis. PLoS One 2020;15:e0237072.

13 Gupta A, Thompson D, Whitehouse A, et al. Adverse events associated with unblinded, but not with blinded, statin therapy in the Anglo-Scandinavian cardiac outcomes Trial-Lipid-Lowering arm (ASCOT-LLA): a randomised double-blind placebo-controlled trial and its non-randomised non-blind extension phase. Lancet 2017;389:2473-81.

14 Hippisley-Cox J, Coupland C. Unintended effects of statins in men and women in England and Wales: population based cohort study using the QResearch database. BMJ 2010;340:c2197.

15 Tascilar K, Dell'Aniello S, Hudson M, et al. Statins and risk of rheumatoid arthritis: a nested case-control study. Arthritis Rheumatol 2016;68:2603-11.

16 Peterson MDH, Crowson CS, Davis JM. Increased risk of rheumatoid arthritis diagnosis in statin users in a large nationwide US study. Annual European Congress of Rheumatology 2020.

17 Myasoedova E, Karmacharya P, Duarte-Garcia A, et al. Effect of statin use on the risk of rheumatoid arthritis: a systematic review and meta-analysis. Semin Arthritis Rheum 2020;50:1348-56.

18 Al-Laith M, Jasenecova M, Abraham S, et al. Arthritis prevention in the pre-clinical phase of RA with abatacept (the APIPPRA study): a multi-centre, randomised, double-blind, parallel-group, placebocontrolled clinical trial protocol. Trials 2019;20:429.

19 Bos WH, Dijkmans BAC, Boers M, et al. Effect of dexamethasone on autoantibody levels and arthritis development in patients with arthralgia: a randomised trial. Ann Rheum Dis 2010;69:571-4.

20 Gerlag DM, Safy M, Maijer KI, et al. Effects of B-cell directed therapy on the preclinical stage of rheumatoid arthritis: the PRAIRI study. Ann Rheum Dis 2019;78:179-85. 